

\section{Anotaciones iniciales}

El humor cinematográfico se ha desplazado desde sus inicios del individuo troupe y no ha girado tanto en torno al juego de dos actores. La primera figura que se internacionaliza como individualidad en el género es el francés Max Linder, quien tuvo su paso, bre ve pero significativo, por Hollywood. Mack Sennett, el creador de la fábrica Keystone, el mayor laboratorio de gags durante el siglo XX, impone el trabajo de equipo, la acción plural, la comiciKeystone cops y las ianlescelebres Keystone cops y las igualmente celerevan gesta británico Charles Chaplin que crea al personaje de Charlot, el principal de todos. Y va surgiendo ese enorme caudal de intérpretes que hicieron dela comedia de tropiezos, caídas, tortazos y persecuciones una de las configuraciones cinematográficas más ricas y vitales del periodo silente.

Si bien hubo presencias femeninas con habilidades humorísticas desde los primeros tiempos, como Mabel Normand o Louise Fazenda, pocas fueron las que alcanzaron un grado de notoriedad o relieve y operaron, más bien, como novias, acompañantes, deseo amoroso o, aveces, adversarias' del protagonista. Desde un inicio, por otra parte, cuando se trataba de hacer una dupla humorística, se impuso la pareja del mismo sexo, invariablemente hombres, y no hubo tampoco ninguna subgénero que hom mención la comedia decómicos conocida también como la slapstick comedy, en Estados Unidos, o el burlesque en Francia. La pareja Chaplin-Edna Purviancesepuedecitar, pero es un caso especial yatípico. En cambio, la comedia de situaciones sí tuvo parejas decierta estabilidad, no en ese mismo periodo pero si más adelante, Spencer Tracy y Katharine Hepburn, por ejemplo; o como las tuvo el musical, principalmente con Fred Astairey Ginger Rogers.

La tradición de la risa provenía en cense o vodevilesco en el que había un casi absoluto predominio masculino y el slapstick heredaesas raices, demodo queno encontramos una sola pareja femenina que pueda considerarse com representantepopulardel subgénemo.

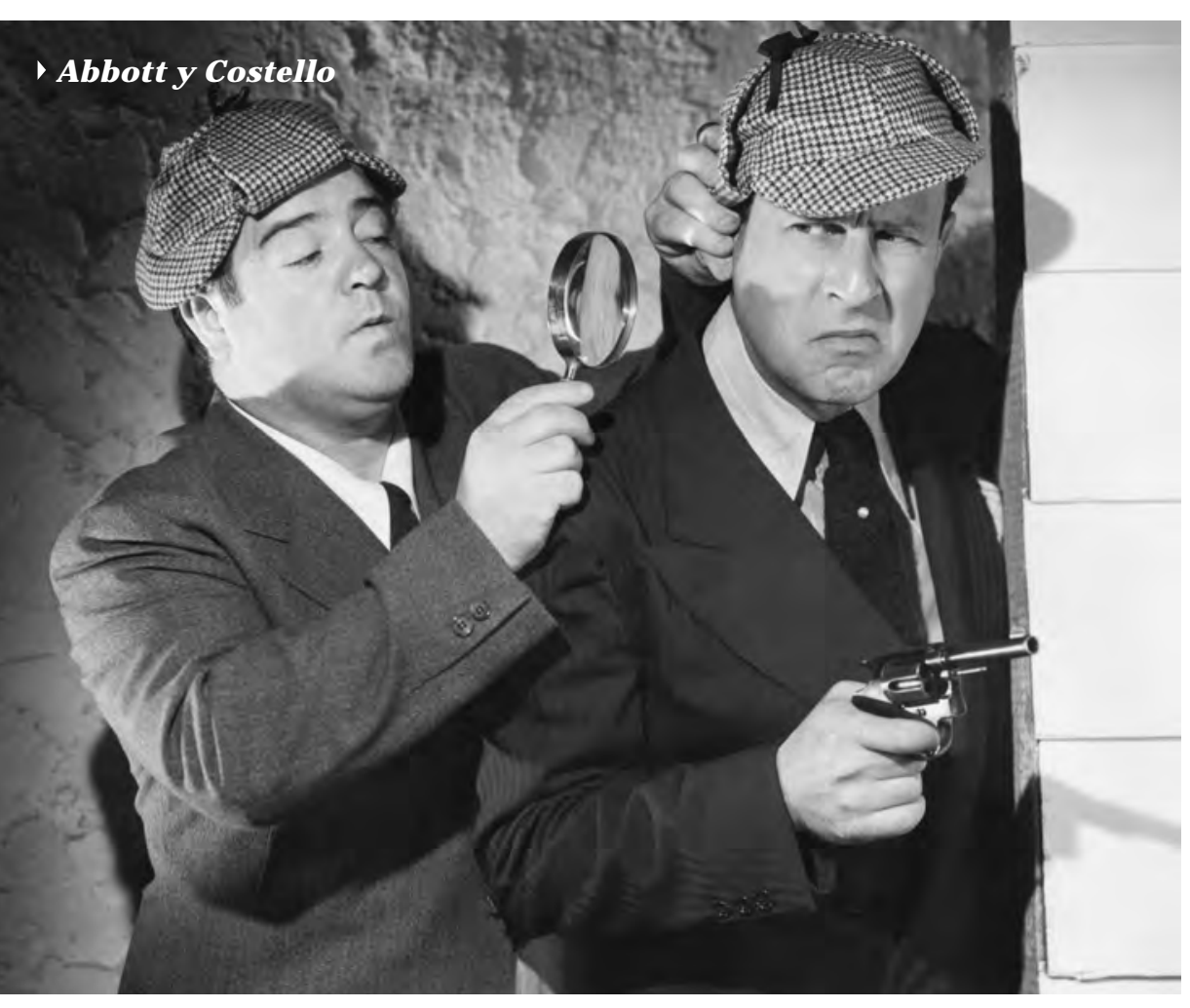

En su momento casi ni se insinuó Laurel y Hardy en los comentarios en torno a los due tos del humor, pero con el tiempo las connotaciones homosexuales se ha hecho más o menos evidentes, aunque en ninguna escena se deslizara nada

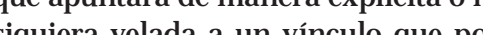
entonces estaba considerado sociatmente proscrito Sin embargo, Laum y Hardy dormín con frecuencia Hardy dormian con frecuencia tidianidad que podría servir hoy de ejemplo para el proyecto de unión civil. En ellos, como en los que vendrán después, el dúo Budd Abbott y Lou Costello oJ erry Lewis y Dean Martin, para limitarnos al panorama de $\mathrm{H}$ lywood, se puede observar, incluso el juego de roles 'masculino' $y$ 'feme nino, así como conductas de dominio, sido $y$ son comunes entre que ha hombre-mujer. Advierto que pareja interés del tema no lo voy a considerar en este breve informe de carácter panorámico. Y bueno, como la razón deser de este artículo, en la tónica que predomina en este número de Ventana Indiscreta, son las parejas cómicas, dejo de lado las individualidades de todos los tiempos, los tríos (los hermanos Marx o los tres chiflados - th three stooges) o grupos como los bortánicos Monty Python y otros.
Fue el otro gran artífice de la edad de oro de la comedia, Hal Roach quie glés Stan Laurel y al norteamerican Oliver Hardy quienes seconvertirá en la gran pareja cómica de los años finales del cine mudo, y en cuya consolidación artística cuenta mucho la los dirigió en unos casos, creó gags para ellos en otros y estuvo muy ligado al despegue del 'gordo y el flaco', como se les conoció en América Latina y España. El dúo se afianza, primero en el corto y más adelante en el largometraje. La incorporación del sonido que tanto daño le hizo a la comedia silente, la mayor víctima gestual y corporal, no afectó de manera sustancial y menos liquidó la carrerá de Laurel y Hardy. Como sín

A diferencia de sus congéneres que Aeron terminada o fuertemente disminuida su carrera, ellos continuaron su andadura y es en el periodo parte de los veintisiete largometrajes conjuntos que tienen en su haber intervención de Leo McCarey: quier de ese cambio tecnológico que afectó las bases mismas de la comicidasonoro en el que realizan la mayo hasta Stan y Oliver toreros en 1945 Cierto, sin el extraordinario nive que habian alcanzado cuando imagen era silente, pero manteniendo, mal que bien, los recursos quelos habian hecho populares en un funcionamiento narrativo que trató hasta quésta fue to carga verbal hasta que ésta fue tomando espacios mayores y el declive de la pareja sus cortos, Oliver y Stan impusiero ticiones y variaciones es cions y variánes es llevada a manteniendo siem, exprón 'yo no hice nada' y culminasio llanto irnernoble de quion, como una suerte de recresión, se convierte o abtido por una cirunstancia des favorable. Mientras que Oliver, con 1 seriedad un tanto caballamesca y pomposa que lo carcterizaba em el prime sorpnendido, atrapado en la vorácine desatada o a veces como la vítima las torpezas de Laurel. empieza a hacerse inevitable. Desde un mituación bant qu simple: es habitualmente, el desenciva. Stan en el niño cádo en falta avengonzado

\section{Abbott y Costello}

Cuando se extenuaba el aliento de Laude los años cuarenta un nuevo dúo que forman Budd Abbott y Lou Coste llo, los nuevos 'el gordo y el flaco', co la particularidad de que en este caso le correspondíaal 'gondo'la partemás activa del humor, a diferencia dela unión Stan (no tan flaco, en realidad), el detonante de las metidas de pata que su compañero Oliver tenía que sobrelle var. Con Abbott y Costello, que prota gonizaron treinta y seis películas entr 1940 y 1956, una nueva dupla levant la bandera del humor en dos cuerpos siendo Costello no solo el activador principal, sino también la figura torp y algo infantilizada (aunque no tanto como Laurel) y Abbott el lado adulto y en su caso un tanto aprovechador la ingenuidad de su companero, con frustrándoseporla innsterninaban llo Abott podí ser nás confor el gordo Oliver pero careća le la homíaytolerancia del acompeñantede Stan Laurel. de Laurel y Hardy donde era el 'flaco'

La Universal, a un promedio de dos films por año, los colocó en ambientes muy variados (del Oeste al desierto, de la guerra a la aventura selvática) pero favoreció una veta muy distinguible

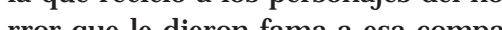
ñ́a en la década precedente y de salen los mejones productos del dú los quemezclan humory hormor con la presencia de alounos de los 'capos' de cine fantástico de esa compañía (Bela Lugosi, Boris Karloff, Lon Chaney, John Carradine), con mayor énfasis ciertamente en el primero. A la mane ra de una versión fílmica de la mezcla de cuentos chistosos y otros de miedo Abbott y Costello se desplazaron po casonas abandonadas, castillos decré pitos, criptas y cementerios, tropezando con vampiros, fantasmas y otros seres de ultratumba.

\section{Lewis y Martin}

Cuando aún Abbotty Costello constituían el soporte mayor de la comedia

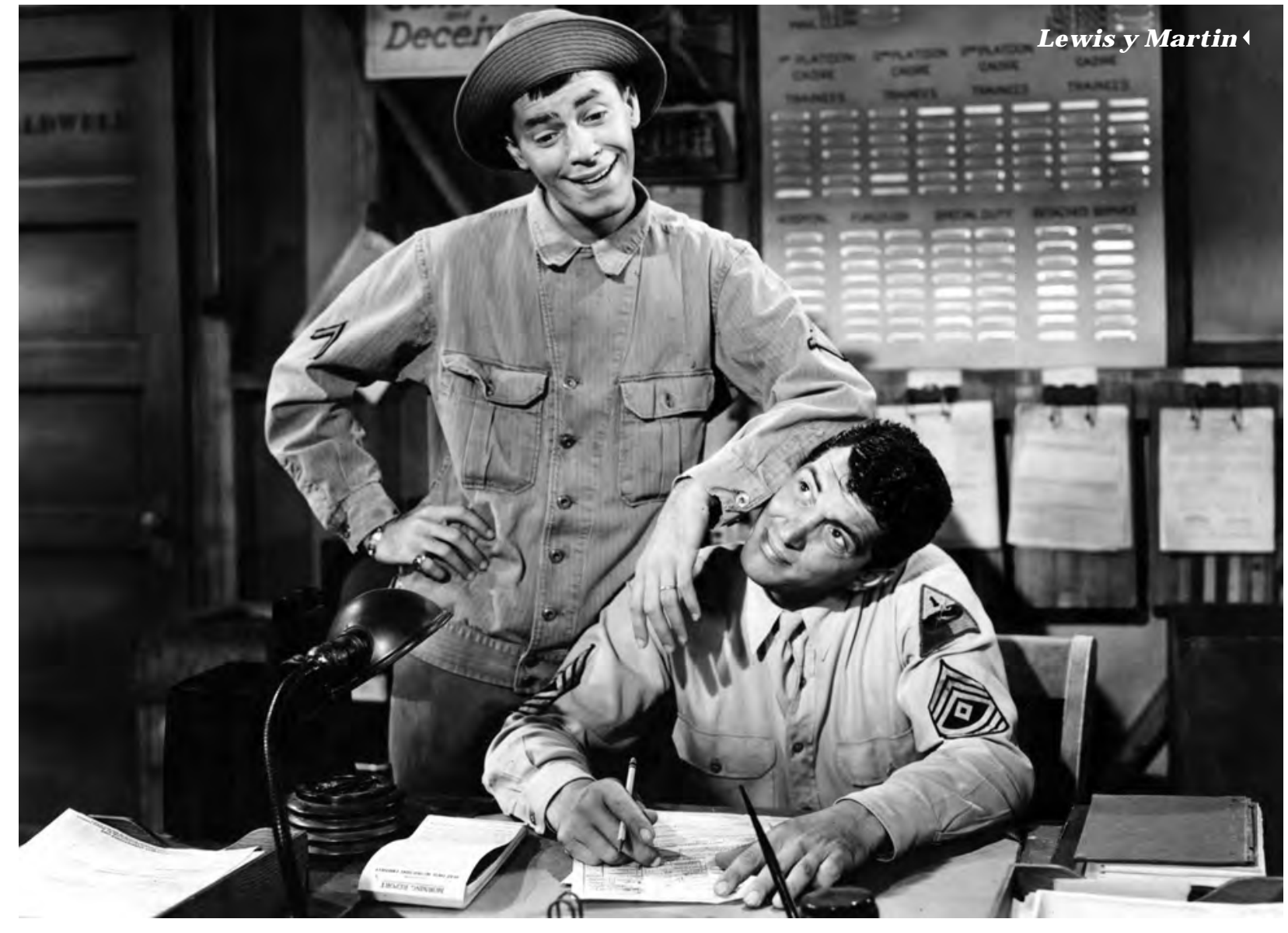


a una nueva pareja, el cómico Jerry Lewis y el cantante Dean Martin,
que venían del espectáculo en vivo, para componer un vínculo en el que la parte humorística se le asigna al primero, y la cuota romántica y muinicio, el centro principal de la acción, demostrando una vez más que la vena cómica favorecía la atención de la audiencia. Ya se advertía, además, que el personaje de 'Lelo', como se le conocio en estas tierras, ofrecía un registro que renovaba algunas fuentes de la slapstick comedy, lo que se acentúa en las películas que díme Frank Tashlin, antes de que el cómico prosiga su andadura indivi-
dualmente y pase a ser la gran figura del humor en el cine norteamericano. Algo opacado por su partner, Martin, 'Lalo' entre nosotros, pasaba por ser una suerte de hermano matado J erry.

Que hayan hecho dieciseis pelí culas juntos entre 1949 y 1956 (un cosa, y es probable que, si el impulso de Lewis hacia la autonomía no se hubiera impuesto así como las dificultades que se fueron presentando entre ellos, con la alta cuota de popularidad a mediados de los años cincuenta, podrian haber continuado unidos. Jerry Lewis revivió la figura del clown que a su modo representaron Stan Laurel y Lou Costello, apotó una movilidad corporal y una capacidad atlética que no tuvieron sus predecesores, además de un registro prácticamente una modalida sonora propia Ante esa personalidad tan acusada Martin parecía débil y afectado pese a su atractivo físico y a su aire seductor y simpático.

\section{Parejas fugaces en}

Hollywood

No se ha repetido ningún dueto similar en el cine de Hollywood. Las parejas comicas han sido temporales o intermitentes, como la de Jack Lemmon y Walter Mathau en comedias de Billy Wilder $\mathrm{y}$ alguna más. $\mathrm{O}$ Aykroid, notables en Los hermanos Caradura (1980). Más recientemente Ben Stiller y Owen Wilson, el mismo
Wilson al lado de Vince Vaughn, o J im Carrey junto con Jeff Daniels, entre nos pasajeros, pues es más propio de

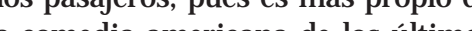
veinte años o bien el protagonism individual (el caso del mismo Carrey) ol grupal. También se pueden mencionar los buddy film, muy trajinados en las últimas décadas y no siemp comedias stricto sensu, donde se encuentran desde thrillers como $48 \mathrm{ho-}$ ras, con la pareja Nick NolteEddi Murphy, hastala seriefantástica Hon-

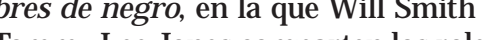
Tonmy LeeJones comparten los roles centrales. Una constante en numerocos por ejemplo a J ackie Chan.

\section{Totò y Peppino de}

Filippo

Totò, bien se sabe, ha sido uno de los más extraordinarios bufos de la historia del cine y fue el centro de numerosas películas quelo tuvieron a cabeza de un reparto en el que otra figuras del cine itallano orbitaron, redor del pequeño intép siempre fue así, pues a veces Toto compartió provechosamente el protagonismo. Por ejemplo en Polićas ladrones (Guardi eladri, Steno y Mario Monicelli, 1951) tuvo como partner nada menos que a Aldo Fabrizz siempre idoneo tanto para los roles dramáticos como los cómicos. No único filme en el que hizo pa-
juntos en más de cien películas du-

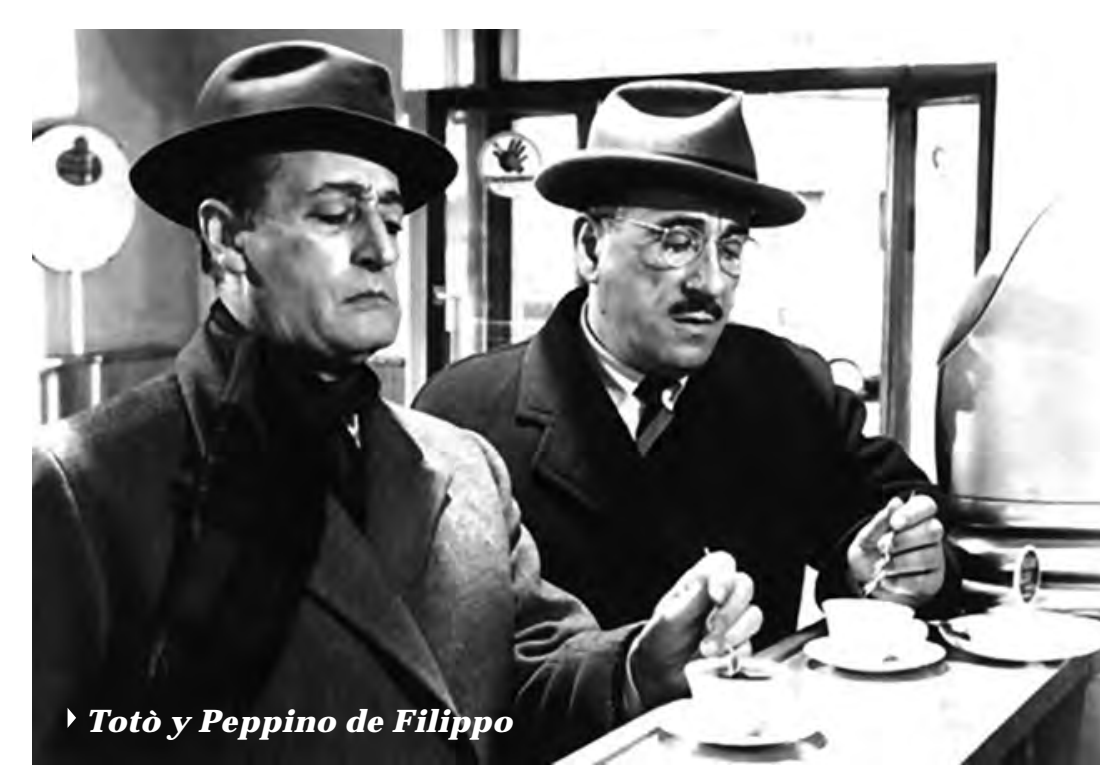

eja protagónica con Fabrizi. En otros ittorio de Sica, a Walter Chairi. Y en Nineto Davili to fos fims que hito con Pier Paolo Pasolini.

Sin embargo, y dentro de la tónhubo un compañero que se repitió en Peppino, Totò pergeñó uma él. Con parodias que los convierten en los primeros on el cine peninsular acometer de manera constante este . no se puede hablar en propiedad de una pareja cómica estable, pues aunque personalizaron desde el titulo varias de las parodias que hicieron pran cónicos que se desplazaban de prupl Va recordar algunos de todos modos

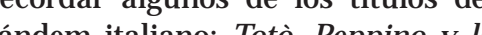
in jidos, Toto y Peppino divisan Berlin Totò, Peppino . y la dolce vita, Totò Peppino y los fanáticos.

\section{Franco Franchi y}

\section{Ciccio Ingrassia}

La más prolongada y prolífica pareja casos, tuvo a Eduardo De Filippo, Tońt ca poliactoral que preside sus films, varias cintas. el coterráneo Peppino tipo de metaversiones en clave bufa, adelantándose a lo que más tarde harán Franchi e Ingrassia. De cualquie

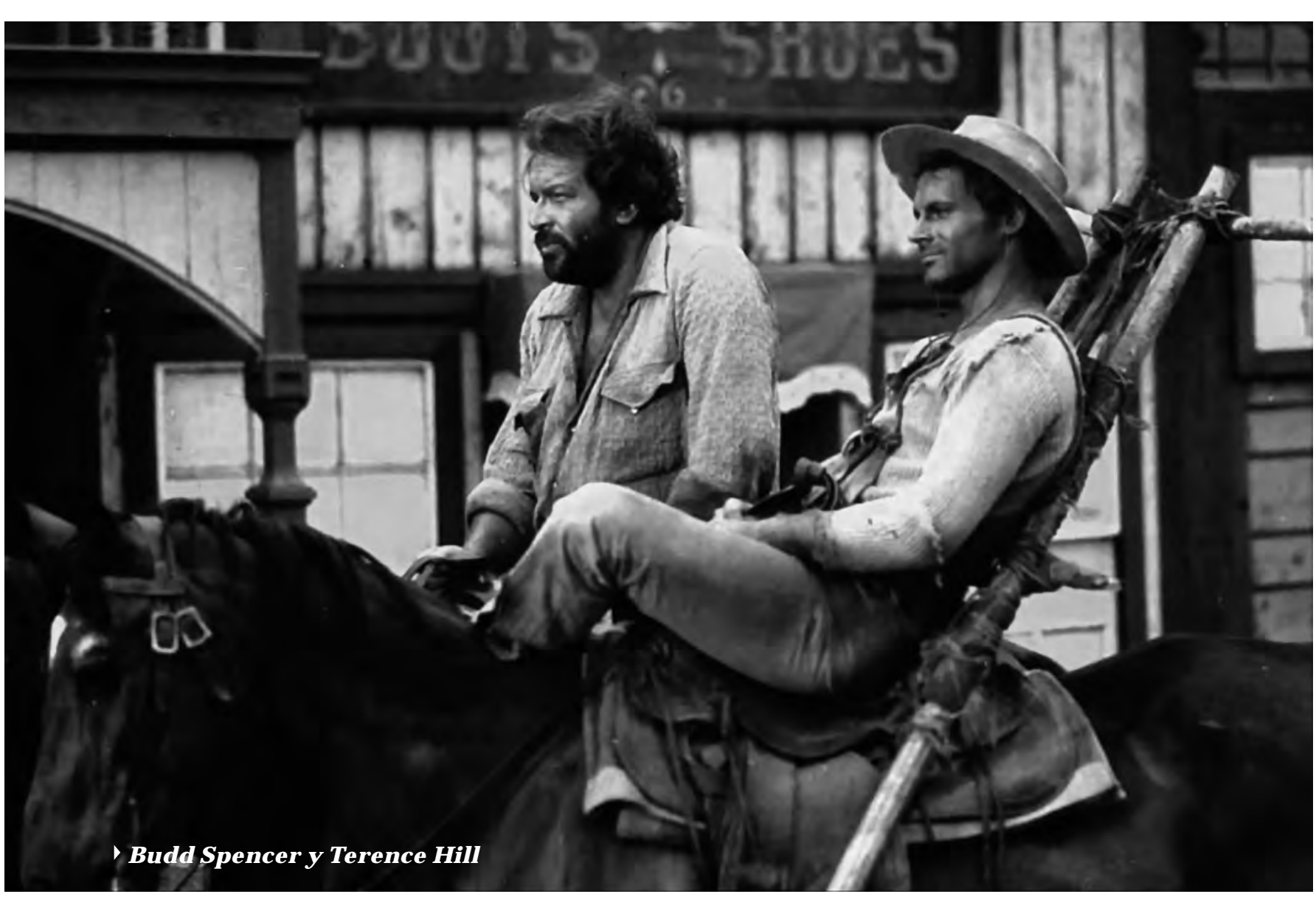

rante veinte años (en las décadas del Budd Spencer y Terence sesenta y setenta) y se especializaron Hill

caricaturescos de persona ferentes de la celtura dop ciento el la cultura popular. Por tos de sú́s según westenon im rela to por la serie James Bond, los pe plum plunén los fins déán bueres y otros ria prima de la que se nutrieron par dar forma a una copiosa filmografí. Pero también el cine de autor lo que hicieron asimismo Totò y De Filippo.

Ingrassia, de estatura alta y de cuerpo delgado y huesudo, proporcionó la nota de esmerada seriedad mientras que Franchi, gordito y plicidad tosca De un tono de simsurció la clave del humbión de esta pareja sicilian. La figura alargada y un tanto quijotesca de Ingrassia se asocioba a una expre sión adusta en tanto que en Franch estallaba la gracia $y$ por cierto, los errores $\mathrm{y}$ torpezas.
Producto del spaguetti western que desde un inicio, exhibió un filón humoristico, nace esta dupla que alcanzó los años setenta con alounos título especialmente exitosos: Dios perdona... ivo no! (1967); Los cuatro de Ave María (1968); Me llaman Trinity (1970): Juntos son dinamita (1974) entre otros. Spencer (Carlo Pedersoli) y Hill (Mario Girotti), quienes venía de desempeñar roles por separado, se unieron utilizando, como era comú el subgénero del oeste peninsular nombres y apellidos en inglés, lo que to solo sediffindió en los actores, sino también en los directores y en otros del de la reación. A diferencia paridos por duo cre tín comSpencer y Hill filmaron juntos sobsieciocho, lo que no es poco, claro, y me alcanzaron, lo que no se puede decir de aquellos que constituyen la obra de Franchi-Ingrassia, comparativamente menos exitosos y algo más intercambiables entre si. Es decir, la producción de' nos años), du romás películas en alguen su producción Spencer y Hill y que explica la mayor carga de rut, y que se puede apreciar en buena parte de la obra de Franchi-Ingrassia.

Spencer y Hill potenciaron ese costado sarcastico y burlón que era propio de la variante italiana del Oeste desde que sus iniciadores, entre ellos Sergio Leone en la llanada trilogía del dólar, lo incorporaron como un rasgo idiode irrespeto e irrisión a una tradición que no era propia pero que se convirtió en una de las líneas más distinguibles del cineitaliano por un periodo de quince años.

Louis de Funes

\section{y Bourvil}

Para no dejar a Francia fuera, selecciono a dos actores que uera, selecaśí la canca pańdica y el componente 
ron unas pocas actuaciones conjuntas pero demostraron en ellas que podian haber formado una unión más estable. Ellos fueron Louis de Funes y Bourvil. Las carreras de siguieron su propio derrotero e incluso Bourvil no se limitó a los roles cómicos, pues entregó, también, desempeños dramáticos, aunque el registro dominante a lo largo de su carrera fue la comedia. En el caso de Louis de Funes no hubo registro dramático posible, pues se concentró en el humor en exclusividad.

Las pocas películas que compartieron (entre ellas, La fuga fantástica (La grande vadrouille, 1966) y El papanatas (Le corniaud, 1965), ambas de Gerard Oury, se encuentran entre las más vistas durante su estreno en la historia de la exhibición comercial en Francia. Porque, y pese a que Bourvil especialmente tuvo roles más sofisticados, se trata de dos actores de enorme popularide yiciestos a ejercer un estilo ción del slapstick pero asimismo en el humor francés que tuvo entre sus exponentes clásicos a Fernandel y a Raimu.

En rigor, con Fernandel, Louis de Funes y Bourvil forman el trío m Como Totò en Italia, Fernandel ha sido la figura mayor del humor en su país, y además con rasgos físicos tan curiosos y peculiares como los de su colega italiano, aunque muy distintos entre sí. Empezó trabajando nada menos que con Marcel Pagnol y Sacha Guitry y fue ganando progresivamente autonomia configurando un personaje unico y secundado por figuras de menor relieve. No obstante, y así como Toto, Fernandel tuvo contrapartes de mayor peso, como millo en el due Fernandel hiz Cacura del mismo nombre mientras que Cervi era el alcalde comunista del pueblo Con Bourvil hizo una comedia en tándem, La mujer con dos maridos (La cuisine au berre, Gilles Grangier, 1963).

Tin Tan y Marcelo

Germán Valdez, Tin Tan, es para muchos de los especialistas mexicanos,

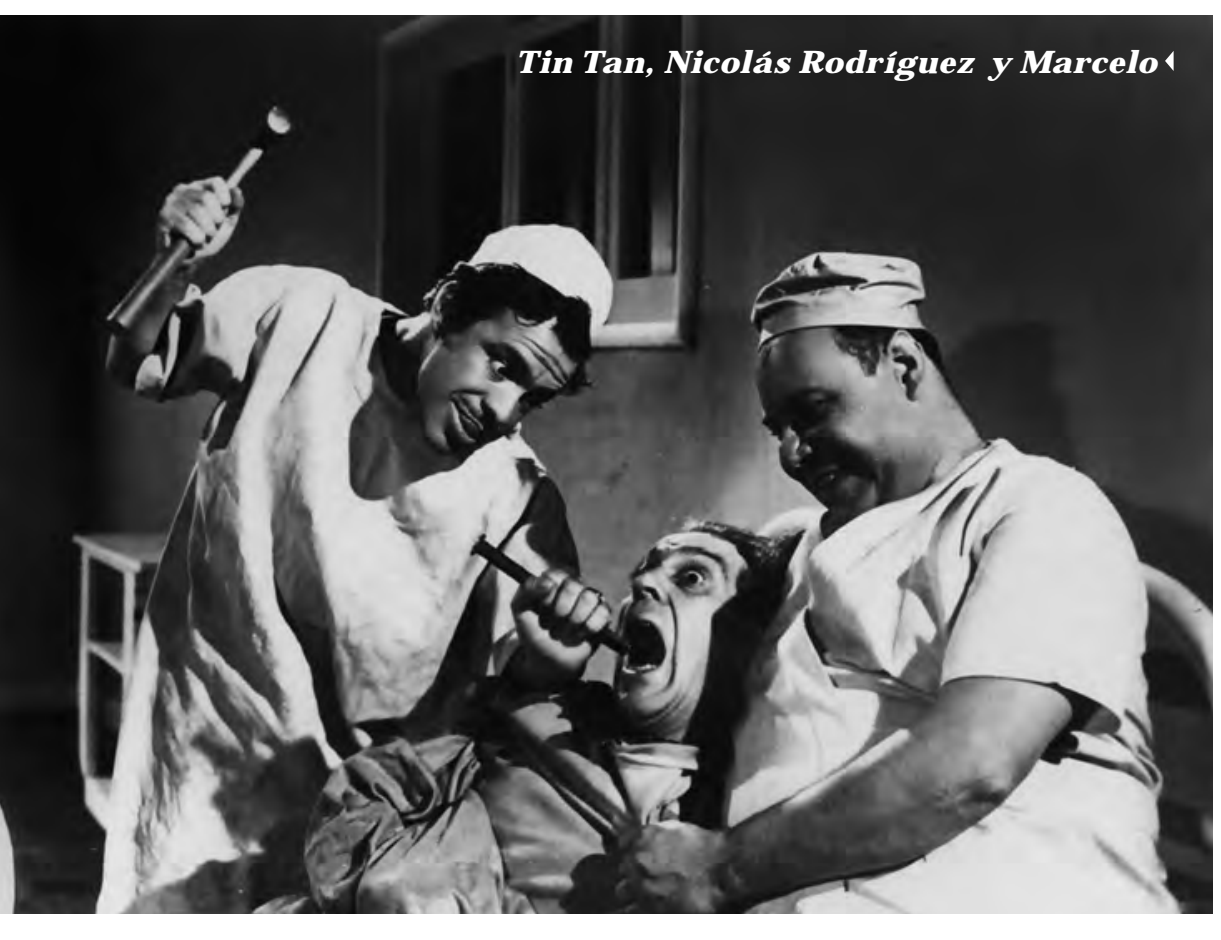

el mejor humoristafílmico con queha contado el país del norte, superando exhibió suino humor popular al que yendo las más celebradas: Calabacino, Cantinflas. En el caso de Tin Tan, (1950); El revoltoso (1951), Me traes que en sus mejores cintas tuvo acom- de un ala (1953); No me defiendas pañantes tan dotados como la actriz compadre (1949); Simbad el made origen canadiense Vitola, tal vez reado (1950); Chucho el remendado a mejor exponente femenina del humor en América Latina, no se puede ublar de que haya tenido en rigor tha pareja cómica. Sin embargo, hizo las veces de un amigo cercano cuando se le necesitaba, sin tener los atributos de otros compañeros reseñados en este pequeño informe No estaba en condiciones de restarle cartel a Tin Tan y tuvo un desempe ño comparativamente mucho más discreto, pues la personalidad fílm ca de Valdez era desbordada y unía a su abundancia oral, una gestualida muy marcada (lo que no ocurría con Cantinflas, por ejemplo) y unas dote para el bailey el desempeño escéni

Más bien una figura complementaria del protagonista, Marcelo hacia sino facilitar, casi por om sión, el lucimiento del pachuco qu compuso Tin Tan, siempre presumido y ostentoso, pero sin perder carisma y la simpatía que lo hiciero cherión blante americana.

\section{Viruta y Capulina}

Fueron el equivalente mexicano de los italianos Franchi e Ingrassia, y no porque cultivaran el mismo con-

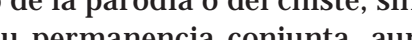
por su permanencia conjunta, aunque el volumen de títulos en común del otro lado del Atlántico. Otra cosa que los enlaza con la pareja italiana ños fílmicos. Aclaro, por si hace falta, que si hay algo que unifica a toda las parejas que mencionamos, ade es precisamente la vocación popular pero digamos que hay grados en Viruta (Marco Antonio Campos) y Capulina (Gaspar Henaine), como en sus congéneres peninsulares, no hubo el menor asomo de sofisticación, pues apelaron principalmente una audiencia poco ilustrada; y más que podían tener, la comicidad que es la vocación popular de sus empeallá de las capacidades expresivas sin ser como se desprende del mismo título del film que los consolidó com pareja interpro

Como en otros duetos similares, los rasgos de uno y otro fuero contrastantes. Mientras Viruta, contextura delgada, era la versió 'seria', el rollizo Capulina constituia el lado bufonesco. El modelo de Laurel y Hardy estaba presente pero los comicos mexicanos fuero instalando su propio registro, rúsbasto. Quería ser un hum vulgar o en una época en que la coprola todavía no esentabu la coprolatia espacio de la gran pantalla.

\section{Porcel y Olmedo}

La dupla argentina, muy activa en la década de 1970 semovió, a diferencia cos, en el terreno del humor 'picante' es decir, asociado al erotismo y, por tanto, proclive al doble sentido, a la presentantes de la llamada comedia adulta, que no cultivó ninguna de las parejas precedentes. Acompañados convocatoria su su monto (Susar Giménez Moira Cason, entre otras Jorge Porcel y Alberto Olmedo se prodigaron en las miradas, los guiños y las alusiones cargados de lascivio También en este caso, una relación no exhaustiva de los títulos es bastante elocuente de lo que el espectador podía esperar: Los caballeros de la cama redonda (1973); Los doctores las prefieren desnudas (1973) Los hombres solo piensan en eso (1976); Fotógrafo de señoras (1978) Expertos en pinchazos (1979); Así no hay cama que aguante (1980); A los cirujanos se les va la mano (1980) Por los títulos se puede inferir, ade más, una preferencia por los roles de lo que les facilitaba el juego de malentendidos con las opulentas damas que los visitaban en los consultorios o clinicas. Sin embargo, el sexo solía permanecer en el umbral, sin llega a las ultimas consecuencias, pues se agotaba en la etapa del calentamiento y no llegaba a más, allanándose los equivocos que habrion p

Porcel y Olmedo representan un periodo de 'destape' en el cine argentino, que siguio a una serie de comedias previas que se inicio con La cigarra no es un bicho (1963) ambientadas en moteles (en los llamados 'hoteles alojamiento' en ese pais), con un protagonismo grupa y con equivocos de parejas. Allí se solto una vertiente erótica que la dupla Porcel-Olmedo va a retomar y en cierto modo magnificar, pese a que finalmente no daba lo que prometía y se resolvia en un humo sexual interruptus.

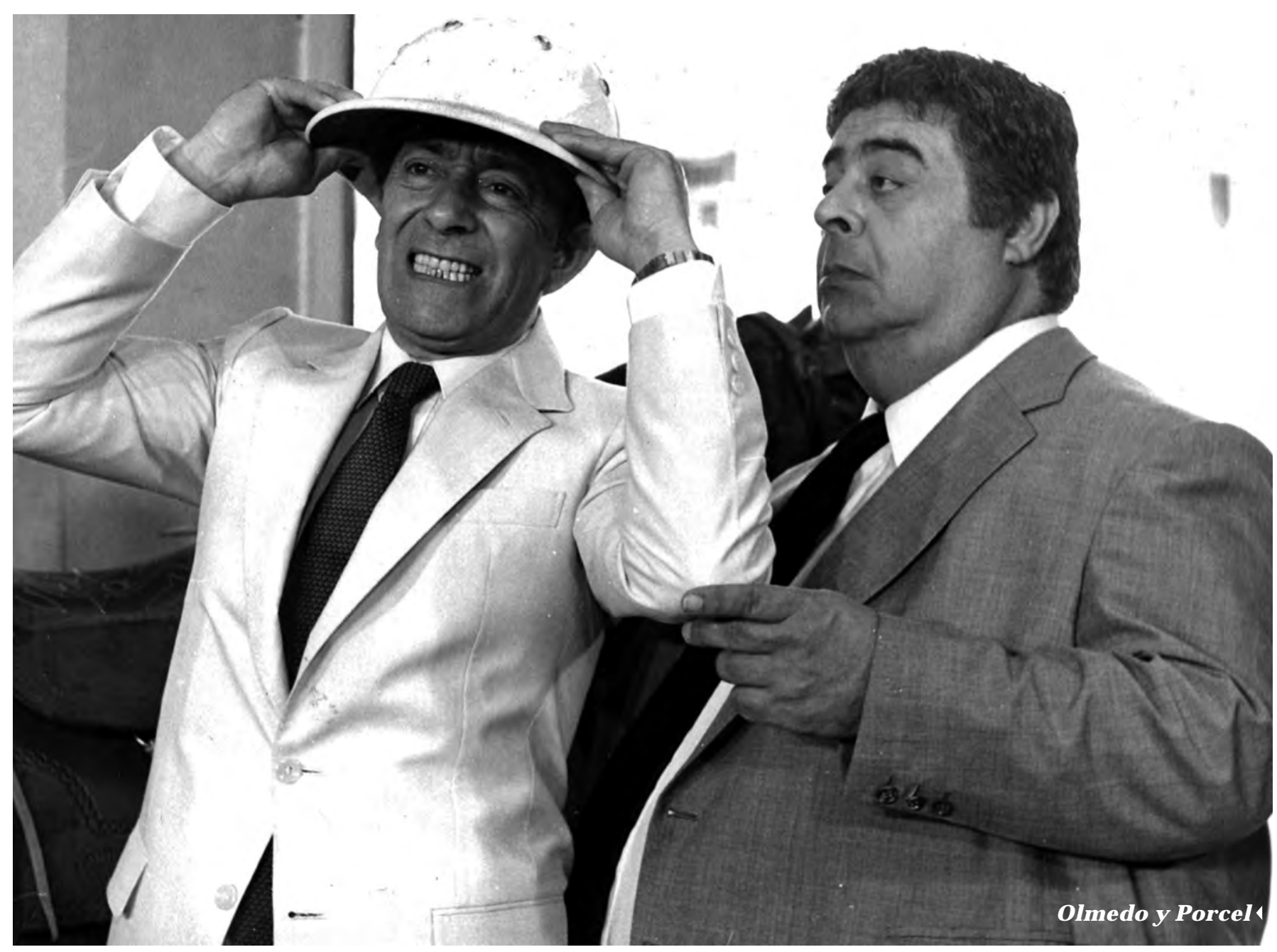

